\title{
PENGARUH DIMENSI KUALITAS TERHADAP KEPUASAN NASABAH BANK PEMBANGUNAN DAERAH KALIMANTAN TIMUR CABANG PEMBANTU TANAH KUNING
}

\author{
Machmud Al Amrie ${ }^{1}$, Adi Aspian Nur ${ }^{2}$ \\ ${ }^{1}$ Fakultas Ekonomi, Universitas Kaltara. Jalan Sengkawit, Tanjung Selor, Bulungan, Kalimantan \\ Utara 73212, Indonesia. \\ E-mail : $\underline{\text { machmudalamrie@gmail.com }}$ \\ ${ }^{2}$ Fakultas Ekonomi, Universitas Kaltara. Jalan Sengkawit, Tanjung Selor, Bulungan, Kalimantan \\ Utara 73212, Indonesia. \\ E-mail : adiaspiannur22@gmail.com, Telp +6281351876400
}

\begin{abstract}
Abstrak
Tujuan penelitian adalah (1) menganalisis dan mengetahui bahwa kualitas layanan yang terdiri dari daya tanggap, jaminan, bukti fisik berpengaruh terhadap kepuasan Nasabah Bank Pembangunan Daerah (BPD) Kalimantan Timur Cabang Pembantu Tanah Kuning (2) mengetahui dan menganalisis manakah kualitas layanan yang dominan berpengaruh terhadap kepuasan Nasabah Bank Pembangunan Daerah (BPD) Kalimantan Timur Cabang Pembantu Tanah Kuning.

Hasil perhitungan diperoleh bahwa pengaruh Kualitas layanan berpengaruh terhadap kepuasan Nasabah Bank Pembangunan Daerah (BPD) Kalimantan Timur Cabang Pembantu Tanah Kuning.
\end{abstract}

Kata Kunci : Pelayanan Bank, Kepuasan nasabah

\section{PENDAHULUAN}

Dengan adanya era globalisasi dan perdagangan bebas, sektor perekonomian sangat memegang peranan penting dalam pertumbuhan ekonomi. Di mana sektor perekonomian menjadi tolak ukur kemakmuran suatu Negara. Hal ini selaras dengan apa yang diamanatkan dalam Pancasila dan UUD 1945 yaitu untuk mewujudkan suatu masyarakat yang adil dan makmur. Dalam rangka mendorong pertumbuhan ekonomi, industri perbankan memiliki peran penting dalam perekonomian, yaitu menyediakan dan menyalurkan dana untuk pembangunan ekonomi masyarakat [1]

Menurut UU Perbankan No. 10 Tahun 1998, bank adalah badan usaha yang menghimpun dana dari masyarakat dalam bentuk simpanan dan menyalurkannya kepada masyarakat dalam bentuk kredit atau bentuk-bentuk lainnya dalam rangka meningkatkan taraf hidup orang banyak. Oleh karena itu, peranan perbankan sangat mempengaruhi kegiatan ekonomi suatu Negara. Semakin maju suatu Negara maka semakin besar peranan perbankan dalam mengendalikan ekonomi Negara tersebut [1] 
Bank merupakan suatu lembaga keuangan yang menghimpun dan menyalurkan dana dari dan kepada masyarakat. Pada krisis ekonomi pada tahun 1997 yang melanda Indonesia beberapa waktu lalu, pemerintah Indonesia melakukan likuidasi besar-besaran terhadap perbankan yang tidak sehat dan tidak dapat melakukan marger penggabungan beberapa bank. Akibat dari kebijakan pemerintah tersebut banyak bank yang sudah tidak beroperasi lagi dan terancam bangkrut. Pemerintah berusaha memperbaiki kondisi perbankan yang masih dapat beroperasi dengan program penyehatan perbankan melalui perubahan manajemen perbankan dan memperbaiki kinerja dari perbankan serta pengawasan yang ketat dari pemerintah untuk perbankan yang ada [2]

Persaingan antar bank memicu tindakan perbankan untuk berlomba-lomba meningkatkan kinerja bank dan meningkatkan kinerja pelayanan. Beberapa kelompok bank swasta mencoba mengambil alih dominasi perbankan dari tangan bank-bank pemerintah. Sejak itu, pertumbuhan bank swasta makin maju, hegemoni bank swasta bakal makin mendominasi pada masa mendatang sebagian besar mereka telah mantap fokus bisnisnya dan mendapat sokongan dari lembaga-lembaga keuangan internasional yang memiliki modal kuat dan berpengalaman besaing di tingkat global [2]

Bank Pembangunan Daerah (BPD) Kalimantan Timur Cabang Pembantu Tanah Kuning merupakan salah satu dari jasa-jasa perbankan yang berada di daerah Tanah Kuning wilayah Kalimantan Utara. Visi dari bank BPD adalah "Menjadi The True Regional Champion dari Kalimantan melalui Produk, Layanan, dan Reputasi Setara Bank Nasional". Sedangkan misi dari bank BPD adalah (1) Berpartisipasi Aktif dalam Pertumbuhan dan Penentuan Pembangunan Ekonomi Kalimantan Timur dan Kalimantan Utara; (2) "Menopang Pengembangan Pembangunan Ekonomi di Seluruh Daerah Kalimantan; (3) Mendukung Pembangunan Ekonomi di seluruh wilayah Indonesia [3]

Mutu pelayanan nasabah di Bank Pembangunan Daerah (BPD) Kalimantan Timur Cabang Pembantu Tanah Kuning sampai pada saat ini dirasakan masih belum optimal karena berdasarkan hasil penelitian saya, masih terdapat konsumen yang merasa kurang puas terhadap Customer service yang sangat lamban dan membutuhkan proses yang lama. Hal ini bisa disebabkan oleh keterbatasan teknologi komputer untuk melayani nasabah, atau mungkin juga keterbatasan tenaga kerja untuk melayani nasabah. Ini menjadi suatu masalah yang cukup rumit yang dialami oleh bank-bank yang berada di daerah [3]

Oleh karena itu, untuk menjawab permasalahan Bank Pembangunan Daerah (BPD) Kalimantan Timur Cabang Pembantu Tanah Kuning konsep kualitas pelayanan menuju pada kepuasan nasabah menarik untuk dikaji. Pelayanan nasabah hendaknya diarahkan pada pelayanan yang berkesinambungan dan pelayanan yang berorientasi pada nasabah yang artinya perusahaan melakukan interaksi yang continue dengan pelayanan yang disertai umpan balik sebagai kontrol dan ukuran keberhasilan perusahaan [3]

Berhasil tidaknya Bank Pembangunan Daerah (BPD) Kalimantan Timur Cabang Pembantu Tanah Kuning memenuhi kebutuhan, keinginan serta kepuasan nasabahnya akan sangat bergantung pada beberapa faktor, salah satunya yaitu pelayanan yang diberikan oleh Bank Pembangunan Daerah (BPD) Kalimantan Timur Cabang Pembantu Tanah Kuning kepada nasabahnya [3]

\section{METODE}

\section{Populasi dan Sampel}

Populasi adalah kelompok elemen yang lengkap, umumnya berupa orang, obyek, transaksi atau kejadian, di mana peneliti mempelajari atau menjadikannya obyek penelitian. Populasi merupakan jumlah keseluruhan dari objek penelitian yaitu nasabah dari Bank Pembangunan Daerah (BPD) Kalimantan Timur Cabang Pembantu Tanah Kuning. Jumlah nasabah bank selama 1 tahun sebanyak 1200 nasabah. Apabila diambil secara triwulan maka jumlah populasi sebanyak 300 nasabah

Sampel adalah suatu himpunan atau bagian dari unit populasi. Pemilihan sampel dilakukan dengan menggunakan stratified random sampling yaitu sampling acak dengan objek yang terstruktur yaitu nasabah pada Bank Pembangunan Daerah (BPD) Kalimantan Timur Cabang Pembantu Tanah Kuning. Sehingga jumlah sebanyak 171 nasabah. 


\section{Jenis dan Sumber Data \\ Data Primer}

Data primer adalah data yang diperoleh melalui hasil penelitian langsung terhadap obyek yang diteliti. Data tersebut diperoleh melalui metode wawancara, observasi dan hasil kuesioner dari responden.

\section{Data Sekunder}

Data Sekunder adalah data yang diperoleh dari berbagai sumber antara lain dari dokumentasi/tulisan (buku-buku, laporan-laporan, karya ilmiah dan hasil penelitian) dan dari informasi pihak-pihak yang berkaitan dengan kajian yang diteliti (uraian tugas, tata kerja dan referensi lainnya).

\section{Teknik Pengumpulan Data}

Metode pengumpulan data dalam penelitian ini dimaksudkan untuk memperoleh data yang relevan dan akurat dengan masalah yang dibahas. Metode pengumpulan data tersebut adalah sebagai berikut:

\section{Observasi}

Observasi adalah metode dipergunakan sebagai salah satu piranti dalam pengumpulan data berdasarkan pengamatan secara langsung pengaruh kualitas layanan terhadap kepuasan nasabah Bank Pembangunan Daerah (BPD) Kalimantan Timur Cabang Pembantu Tanah Kuning.

\section{Wawancara}

Wawancara yaitu dialog secara langsung untuk memperoleh informasi dari responden terpilih dalam menghimpun informasi yang relevan dengan penelitian yang akan diadakan di Bank Pembangunan Daerah (BPD) Kalimantan Timur Cabang Pembantu Tanah Kuning.

\section{Kuesioner}

Kuesioner adalah teknik pengumpulan data dengan mengajukan sejumlah pertanyaan secara tertulis yang diberikan kepada responden dengan maksud untuk memperoleh data yang akurat dan valid.

\section{Dokumentasi}

Dokumentasi yaitu data yang diperoleh melalui pencatatan-pencatatan dari dokumen-dokumen yang terdapat pada lokasi penelitian maupun photo atau bukti dari responden yang mengisi kuesioner.

\section{Analisis Data}

Inti dari kegiatan pemasaran adalah mengetahui keinginan konsumen serta berusaha memuaskan keinginan tersebut. Konsumen yang puas akan sebuah produk atau jasa mempunyai kecenderungan untuk mengkonsumsi produk atau jasa tersebut berulang kali, hal itu akan menciptakan konsumen yang loyal atau setia. Pada akhirnya konsumen yang loyal akan meningkatkan profit perusahaan.

Dalam penelitian ini juga meneliti tentang kepuasan nasabah dalam menggunakan jasa pelayanan di Bank Pembangunan Daerah (BPD) Kalimantan Timur Cabang Pembantu Tanah Kuning, artinya semakin baik pelayanan yang diberikan maka nasabah akan cenderung untuk loyal atau setia.

Kepuasan konsumen pada dasarnya dipengaruhi oleh dua faktor, yakni harapan konsumen akan kinerja sebuah produk atau jasa, dan kenyataan yang mereka terima setelah mengkonsumsi produk atau jasa tersebut. Konsumen akan merasa puas jika kinerja produk atau jasa sama atau bahkan melebihi harapan semula. Sebaliknya, konsumen akan tidak puas jika kinerja produk/ atau jasa tidak sesuai dengan harapannya [4]

Sebelum melakukan pengukuran, akan ditentukan dahulu atribut-atribut apa saja yang mempengaruhi kepuasan nasabah terhadap pelayanan yang diberikan melalui butir-butir pertanyaan atau kuesioner. Kemudian, pengukuran kepuasan nasabah menggunakan bantuan SPSS dan Excel, ada beberapa metode yang dapat digunakan, yaitu :

1. Teknik Pengukuran dengan indeks;

2. Teknik pengukuran melalui grafik; 


\subsection{Teknik Pengukuran dengan indeks}

Indeks kepuasan nasabah adalah sebuah angka yang menyatakan seberapa besar tingkat kepuasan nasabah akan pelayanan yang diberikan.

Indeks yang digunakan dalam penelitian ini adalah metode CSI (Customer Satisfaction Index).

Merupakan metode pengukuran kepuasan konsumen yang populer dan banyak digunakan pada perusahaan besar. Bisa digunakan untuk membandingkan tingkat kepuasan dua produk atau lebih, maupun melihat perkembangan tingkat kepuasan konsumen akan sebuah produk dari waktu ke waktu (time series).

Caranya :

1. Mengukur tingkat kepentingan dan tingkat kepuasan nasabah akan setiap atribut yang mempengaruhi kepuasan nasabah dengan menggunakan skala. Biasanya digunakan skala Likert.

2. Hitung rata-rata skor kepentingan dan rata-rata skor kepuasan masing-masing atribut. Dengan rumus sebagai berikut :

Di mana :

$$
M I S=\frac{\left(\sum_{i=1}^{n} Y i\right)}{n}
$$

$$
\begin{array}{ll}
\mathrm{N} & \text { : Jumlah Konsumen } \\
\mathrm{Yi} & \text { : Nilai kepentingan Atribut } \mathrm{Y} \text { ke - i }
\end{array}
$$

3. Importance weighting factor diperoleh dari skor masing-masing atribut dibagi total kepentingan seluruh atribut. Dengan rumus sebagai berikut :

Di mana :

$$
W F=\frac{M I S i}{\sum_{i=0}^{n} M I S i} \times 100 \%
$$

MISi : Rata-rata skor kepentingan per atribut

E MISi : Jumlah keseluruhan rata-rata skor kepentingan

4. Weighted score diperoleh dari perkalian importance weighting factor dengan skor kepuasan masing-masing atribut.

Wsi $=$ Wfi $x$ MSS

5. Weighted average diperoleh dari penjumlahan weighted score seluruh atribut.

6. Customer Satisfaction Index diperoleh dari pembagian weighted average

dengan skala maksimum yang digunakan, dalam hal ini skala 5.

Di mana :

$$
C S I=\frac{\sum_{i=0}^{n} W S i}{H S} \times 100 \%
$$

HS : High Scales (skala maksimum yang digunakan)

\subsection{Teknik pengukuran melalui grafik}

Tampilan melalui grafik lebih mudah dipahami dan diinterpretasikan, apalagi jika digunakan untuk membandingkan dua atau lebih produk atau jasa. Cara pengukuran kepuasan konsumen dalam penelitian ini menggunakan Importance Performance Analysis (IPA).

\subsection{Regresi Berganda}

Metode analisis regresi berganda dengan rumus

$$
Y=b_{0}+b_{1} X_{1}+b_{2} X_{2}+b_{3} X_{3}+b_{4} X_{4}+b_{5} X_{5}+e_{i}
$$

Dimana:

$$
\begin{array}{ll}
\mathrm{Y} & =\text { Kepuasan Konsumen } \\
\mathrm{X}_{1} & =\text { Daya tanggap } \\
\mathrm{X}_{2} & =\text { Jaminan } \\
\mathrm{X}_{3} & =\text { Bukti Fisik } \\
\mathrm{X}_{4} & =\text { Empati } \\
\mathrm{X}_{5} & =\text { Handal } \\
\mathrm{b}_{1}, \mathrm{~b}_{2}, \mathrm{~b}_{3}, \mathrm{~b}_{4}, \mathrm{~b}_{5}, & =\text { Koefisien Regresi (Parameter) }
\end{array}
$$


$\mathrm{b}_{0} \quad=$ Konstanta (Intercept)

$\mathrm{e}_{\mathrm{i}} \quad=$ Faktor Kesalahan

Selanjutnya untuk menentukan pengaruh dan tingkat signifikan digunakan $\alpha=0.05$ atau 5\% dapat diuji dengan menggunakan uji-F dan uji-t.

\section{HASIL DAN PEMBAHASAN}

Hasil pengujian validitas dalam penelitian sebagai berikut :

\section{Variabel Motivasi (X1)}

Sebanyak 8 indikator pertanyaan yang dinyatakan dalam bentuk item. Delapan indikator pertanyaan tersebut akan diuji dengan menggunakan Pearson Correlation. Syarat pengujian validitas adalah apabila nilai Sig < 5\% maka diartikan valid dan dapat dipergunakan indikator pertanyaan. Hasil dari uji validitas sebagai berikut.

Table 1 Validitas Variabel Motivasi (X1)

\begin{tabular}{|c|c|c|c|}
\hline & & MOTIVASI & KETERANGAN \\
\hline Item 1 & $\begin{array}{l}\text { Pearson Correlation } \\
\text { Sig. (2-tailed) } \\
\text { N }\end{array}$ & $\begin{array}{r}, 786 \\
, 000 \\
50\end{array}$ & VALID \\
\hline Item 2 & $\begin{array}{l}\text { Pearson Correlation } \\
\text { Sig. (2-tailed) } \\
\text { N }\end{array}$ & $\begin{array}{r}, 796 \\
, 000 \\
50 \\
\end{array}$ & VALID \\
\hline Item 3 & $\begin{array}{l}\text { Pearson Correlation } \\
\text { Sig. (2-tailed) } \\
\mathrm{N} \\
\end{array}$ & $\begin{array}{r}359 \\
, 011 \\
50 \\
\end{array}$ & VALID \\
\hline Item 4 & $\begin{array}{l}\text { Pearson Correlation } \\
\text { Sig. (2-tailed) } \\
\text { N }\end{array}$ & $\begin{array}{r}, 586 \\
, 000 \\
50 \\
\end{array}$ & VALID \\
\hline Item 5 & $\begin{array}{l}\text { Pearson Correlation } \\
\text { Sig. (2-tailed) } \\
\text { N }\end{array}$ & $\begin{array}{r}, 372 \\
, 008 \\
50 \\
\end{array}$ & VALID \\
\hline Item 6 & $\begin{array}{l}\text { Pearson Correlation } \\
\text { Sig. (2-tailed) } \\
\text { N }\end{array}$ & $\begin{array}{r}, 564 \\
, 000 \\
50\end{array}$ & VALID \\
\hline Item 7 & $\begin{array}{l}\text { Pearson Correlation } \\
\text { Sig. (2-tailed) } \\
\text { N }\end{array}$ & $\begin{array}{r}, 790 \\
, 000 \\
50\end{array}$ & VALID \\
\hline
\end{tabular}

Sumber : Hasil pengolahan data

Hasil perhitungan diperoleh bahwa item atau indikator 1, item 2, item 3, item 4, item 5, item 6 serta item 7 adalah valid dan dapat dipergunakan dalam perhitungan statistik. Dasar peneliti menyatakan variabel motivasi (X1) adalah valid dari nilai Sig. (2-tailed) yaitu $<5 \%$, angka 5\% merupakan tingkat kesalahan dari tingkat kepercayaan sebesar $95 \%$.

\section{Variabel Penempatan Kerja (X2)}

Hasil uji validitas untuk variabel disiplin pegawai sebagai berikut.

Table 2 Validitas Variabel Penempatan Kerja (X2)

\begin{tabular}{|ll|r|l|}
\hline & \multicolumn{2}{|c|}{$\begin{array}{c}\text { PENEMPATAN } \\
\text { KERJA }\end{array}$} & KETERANGAN \\
\hline \multirow{4}{*}{ Item 1} & Pearson Correlation &, 868 & \\
& Sig. (2-tailed) &, 000 & VALID \\
& $\mathrm{N}$ & 73 & \\
\hline
\end{tabular}




\begin{tabular}{|c|c|c|c|}
\hline Item 2 & $\begin{array}{l}\text { Pearson Correlation } \\
\text { Sig. (2-tailed) } \\
\text { N }\end{array}$ & $\begin{array}{r}, 857 \\
, 000 \\
73 \\
\end{array}$ & VALID \\
\hline Item 3 & $\begin{array}{l}\text { Pearson Correlation } \\
\text { Sig. (2-tailed) } \\
\mathrm{N}\end{array}$ & $\begin{array}{r}, 903 \\
, 000 \\
73\end{array}$ & VALID \\
\hline Item 4 & $\begin{array}{l}\text { Pearson Correlation } \\
\text { Sig. (2-tailed) } \\
\mathrm{N}\end{array}$ & $\begin{array}{r}, 879 \\
, 000 \\
73 \\
\end{array}$ & VALID \\
\hline Item 5 & $\begin{array}{l}\text { Pearson Correlation } \\
\text { Sig. (2-tailed) } \\
\mathrm{N}\end{array}$ & $\begin{array}{r}, 869 \\
, 000 \\
73\end{array}$ & VALID \\
\hline Item 6 & $\begin{array}{l}\text { Pearson Correlation } \\
\text { Sig. (2-tailed) } \\
\mathrm{N}\end{array}$ & $\begin{array}{r}, 903 \\
, 000 \\
73 \\
\end{array}$ & VALID \\
\hline Item 7 & $\begin{array}{l}\text { Pearson Correlation } \\
\text { Sig. (2-tailed) } \\
\mathrm{N}\end{array}$ & $\begin{array}{r}, 904 \\
, 000 \\
73\end{array}$ & VALID \\
\hline
\end{tabular}

Sumber : Hasil pengolahan data

Hasil perhitungan diperoleh bahwa item atau indikator 1, item 2, item 3, item 4, item 5, item 6 serta item 7 adalah valid dan dapat dipergunakan dalam perhitungan statistik. Dasar peneliti menyatakan variabel penempatan kerja (X2) adalah valid dari nilai Sig. (2-tailed) yaitu < 5\%, angka $5 \%$ merupakan tingkat kesalahan dari tingkat kepercayaan sebesar $95 \%$.

\section{Variabel Kinerja (Y)}

Hasil uji validitas untuk variabel kinerja (Y) sebagai berikut.

Table 3 Validitas Variabel Kinerja (Y)

\begin{tabular}{|ll|r|l|}
\hline & & \multicolumn{1}{|c|}{ KINERJA } & KETERANGAN \\
\hline Item 1 & Pearson Correlation &, 473 & \\
& Sig. (2-tailed) & 700 & VALID \\
& $\mathrm{N}$ &, 723 & \\
\hline Item 2 & Pearson Correlation &, 000 & \\
& Sig. (2-tailed) & 73 & VALID \\
& $\mathrm{N}$ &, 533 & \\
& Pearson Correlation &, 000 & VALID \\
\hline Item 3 & Sig. (2-tailed) & 73 & \\
& $\mathrm{~N}$ &, 675 & \\
& Pearson Correlation &, 000 & VALID \\
\hline Item 4 & Sig. (2-tailed) & 73 & \\
& $\mathrm{~N}$ &, 662 & VALID \\
& Pearson Correlation & & \\
\hline Item 5 & &
\end{tabular}




\begin{tabular}{|c|c|c|c|}
\hline & Sig. (2-tailed) & , 000 & \\
\hline & $\mathrm{N}$ & 73 & \\
\hline Item 6 & Pearson Correlation & ,627 & \\
\hline & Sig. (2-tailed) & ,000 & VALID \\
\hline & $\mathrm{N}$ & 73 & \\
\hline Item 7 & Pearson Correlation & ,498 & \\
\hline & Sig. (2-tailed) & ,000 & VALID \\
\hline & $\mathrm{N}$ & 73 & \\
\hline Item 8 & Pearson Correlation & 619 & \\
\hline & Sig. (2-tailed) & , 000 & VALID \\
\hline & $\mathrm{N}$ & 73 & \\
\hline
\end{tabular}

Sumber : Hasil pengolahan data

Hasil perhitungan diperoleh bahwa item atau indikator 1, item 2 , item 3 , item 4 , item 5 , item 6 , item 7 serta item 8 adalah valid dan dapat dipergunakan dalam perhitungan statistik. Dapat dilihat dari nilai Sig $<5 \%$.

Secara keseluruhan variabel motivasi, variabel penempatan kerja dan variabel kinerja dalam pengujian menggunakan uji validitas semua item-item kuesioner dari masing-masing variabel diperoleh hasil valid, artinya item-item kuesioner mampu menjelaskan dari variabel-variabel yang diteliti yaitu variabel motivasi, variabel penempatan kerja dan variabel kinerja.

Apabila ada nilai yang tidak valid dari item kuesioner maka peneliti mengartikan bahwa item kuesioner tersebut tidak mampu menjelaskan akan variabel yang diteliti dalam penelitian ini.

\section{Uji Realibilitas}

Selanjutnya dilakukan uji realibilitas dengan tujuan untuk menunjukkan sejauh mana suatu hasil pengukuran relatif konsisten apabila pengukuran diulang dua kali atau lebih, suatu kuesioner dikatakan reliabel apabila jawaban seorang sampel terhadap pernyataan bersifat konsisten atau stabil dari waktu ke waktu.

Hasil perhitungan uji realibilitas sebagai berikut :

Table 4 Realibility Test

\begin{tabular}{|c|c|r|r|}
\hline NO & KETERANGAN & Cronbach's Alpha & \multicolumn{2}{|c|}{ N of Items } \\
\hline 1 & $\mathrm{X} 1$ &, 750 & 7 \\
\hline 2 & $\mathrm{X} 2$ &, 951 & 7 \\
\hline 3 & $\mathrm{Y}$ &, 748 & 8 \\
\hline
\end{tabular}

Sumber : Hasil SPSS

Hasil perhitungan dengan menggunakan software statistik diperoleh nilai Cronbach's Alpha sebesar 0,750 untuk X1, 0,951 untuk X2, dan 0,748 untuk Y. Yang memiliki arti Acceptable atau hasil kuesioner dapat diterima dan dipergunakan untuk perhitungan statistik.

Pengertian reliabilitas adalah bahwa kuesioner dalam penelitian ini apabila dilakukan ditempat berbeda dengan responden yang berbeda akan diperoleh hasil yang sama.

\section{Regresi Sederhana (Linear Regression)}

Bentuk persamaan regresi sederhana adalah.

$\widehat{\boldsymbol{Y}}=\mathbf{a}+{ }_{\beta} \cdot \mathbf{X}+\mathbf{e}$

Dimana dalam penelitian menjelaskan bahwa. 


$$
\begin{array}{ll}
\widehat{\boldsymbol{Y}} & =\text { Kepuasan nasabah (Y toping) } \\
\mathrm{X} & =\text { Kualitas pelayanan } \\
\mathrm{e} & =\text { Tingkat Kesalahan }
\end{array}
$$

\begin{tabular}{|c|c|c|c|c|c|c|}
\hline \multicolumn{7}{|c|}{ Coefficients $^{\mathrm{a}}$} \\
\hline \multirow{2}{*}{\multicolumn{2}{|c|}{ Model }} & \multicolumn{2}{|c|}{ Unstandardized Coefficients } & \multirow{2}{*}{$\begin{array}{c}\begin{array}{c}\text { Standardized } \\
\text { Coefficients }\end{array} \\
\text { Beta }\end{array}$} & \multirow[b]{2}{*}{$\mathrm{t}$} & \multirow[b]{2}{*}{ Sig. } \\
\hline & & $\mathrm{B}$ & Std. Error & & & \\
\hline \multirow[t]{2}{*}{1} & (Constant) & 1,407 &, 833 & & 1,690 & ,093 \\
\hline & & ,339 &, 017 & ,843 & 20,364 & ,000 \\
\hline
\end{tabular}

Hasil perhitungan dengan menggunakan software statistik diperoleh sebagai berikut :

Table 5 Persamaan Regresi

a. Dependent Variable: TOTAL Y

Interpretasi sebagai berikut :

$\mathrm{Y}=1,407+0,339 . \mathrm{X}$

Artinya nilai 0,339 merupakan intercept dari X yaitu kualitas pelayanan. Kualitas pelayanan merupakan standar atau dasar kualitas yang harus dilakukan oleh oleh pegawai Bank Pembangunan Daerah (BPD) Kalimantan Timur Cabang Pembantu Tanah Kuning dalam memberikan pelayanan maksimal kepada nasabah. Setiap adanya perubahan kualitas pelayanan maka diasumsikan terjadi peningkatan kepuasan nasabah Bank Pembangunan Daerah (BPD) Kalimantan Timur Cabang Pembantu Tanah Kuning sebesar 0,339.

Hasil uji $\mathbf{t}$ dapat dilihat dari nilai sig pada tabel 4.5 sebesar 0,000 . Syarat apabila suatu variabel signifikan adalah apabila nilai sig < 5\%. Angka 5\% merupakan nilai kesalahan dari tingkat kepercayaan yang peneliti tetapkan terhadap penelitian ini sebesar 95\%. Sehingga dapat diartikan bahwa "Kualitas layanan berpengaruh signifikan terhadap kepuasan Nasabah Bank Pembangunan Daerah (BPD) Kalimantan Timur Cabang Pembantu Tanah Kuning" artinya semakin Bank Pembangunan Daerah (BPD) Kalimantan Timur Cabang Pembantu Tanah Kuning memperhatikan kualitas pelayanan maka nasabah akan semakin merasa puas.

\section{Koefisien Korelasi dan Koefisien Determinasi}

\begin{tabular}{|c|c|c|c|c|}
\hline \multicolumn{5}{|c|}{ Model Summary } \\
\hline Model & $\mathrm{R}$ & R Square & Adjusted R Square & Std. Error of the Estimate \\
\hline dimension0 1 & $843^{\mathrm{a}}$ & ,710 & ,709 & ,74193 \\
\hline
\end{tabular}

Hasil perhitungan koefisien korelasi $(\mathrm{R})$ dan koefisien determinasi $\left(\mathrm{R}^{2}\right)$ sebagai berikut.

Table 6 Koefisien Korelasi dan Koefisien Determinasi

a. Predictors: (Constant), TOTAL X

Koefisien korelasi (R) sebesar 0,843 menunjukkan bahwa tingkat hubungan korelasi antara dimensi pelayanan terhadap kepuasan nasabah adalah sangat kuat. Artinya semakin ditingkatkan dimensi pelayanan maka secara tidak langsung akan meningkatkan kepuasan nasabah dalam melakukan kegiatan transaksi perbankan.

$\mathrm{R}^{2}$ ( $R$ square) sebesar 0,710 artinya setiap terjadi peningkatan pelayanan yang dilakukan oleh Bank Pembangunan Daerah di Tanah Kuning maka akan mempengaruhi perubahan kepuasan nasabah bank sebesar $71 \%$. Sedangkan sisanya $(100 \%-71 \%)$ yaitu $29 \%$ dijelaskan oleh faktor-faktor lain, 
artinya masih banyak ada faktor-faktor lain diluar variabel penelitian yang akan mempengaruji kepuasan nasabah Bank Pembangunan Daerah (BPD) Kalimantan Timur Cabang Pembantu Tanah Kuning.

\section{Pembahasan}

Konsep kualitas layanan pada dasarnya memberikan persepsi secara konkrit atau nyata mengenai kualitas suatu layanan. Konsep kualitas layanan ini merupakan suatu revolusi atau perubahan secara menyeluruh, permanen dalam mengubah cara pandang manusia dalam menjalankan atau mengupayakan usaha-usahanya yang berkaitan dengan proses dinamis, berlangsung, terus menerus di dalam memenuhi harapan, keinginan dan kebutuhan. Hal ini sesuai dengan teori "Quality" yang menjelaskan keberhasilan suatu tindakan jasa ditentukan oleh kualitas. Kualitas merupakan apresiasi tertinggi dari tindakan pelayanan [4]

Konsep kualitas layanan adalah suatu persepsi tentang revolusi kualitas secara menyeluruh yang terpikirkan dan menjadi suatu gagasan yang harus dirumuskan (formulasi) agar penerapannya (implementasi) dapat diuji kembali (evaluasi), untuk menjadi suatu proses yang dinamis, berlangsung, terus menerus dalam memenuhi kepuasan pelanggan.

Hasil penelitian diperoleh nilai 0,339 untuk kualitas pelayanan. Kualitas pelayanan merupakan standar atau dasar kualitas yang harus dilakukan oleh oleh pegawai Bank Pembangunan Daerah (BPD) Kalimantan Timur Cabang Pembantu Tanah Kuning dalam memberikan pelayanan maksimal kepada nasabah. Setiap adanya perubahan kualitas pelayanan maka diasumsikan terjadi peningkatan kepuasan nasabah Bank Pembangunan Daerah (BPD) Kalimantan Timur Cabang Pembantu Tanah Kuning sebesar 0,339 .

Hasil penelitian ini juga didukung oleh pengujian-uji $t$ dapat dilihat dari nilai sig sebesar 0,000 . Syarat apabila suatu variabel signifikan adalah apabila nilai sig $<5 \%$. Sehingga dapat diartikan bahwa "Kualitas layanan berpengaruh signifikan terhadap kepuasan Nasabah Bank Pembangunan Daerah (BPD) Kalimantan Timur Cabang Pembantu Tanah Kuning" artinya semakin Bank Pembangunan Daerah (BPD) Kalimantan Timur Cabang Pembantu Tanah Kuning memperhatikan kualitas pelayanan maka nasabah akan semakin merasa puas.

Koefisien korelasi (R) sebesar 0,843 menunjukkan bahwa tingkat hubungan korelasi antara dimensi pelayanan terhadap kepuasan nasabah adalah sangat kuat. Artinya semakin ditingkatkan dimensi pelayanan maka secara tidak langsung akan meningkatkan kepuasan nasabah dalam melakukan kegiatan transaksi perbankan.

$\mathrm{R}^{2}$ (R square) sebesar 0,710 artinya setiap terjadi peningkatan pelayanan yang dilakukan oleh Bank Pembangunan Daerah di Tanah Kuning maka akan mempengaruhi perubahan kepuasan nasabah bank sebesar $71 \%$. Sedangkan sisanya $(100 \%-71 \%)$ yaitu $29 \%$ dijelaskan oleh faktor-faktor lain, artinya masih banyak ada faktor-faktor lain diluar variabel penelitian yang akan mempengaruji kepuasan nasabah Bank Pembangunan Daerah (BPD) Kalimantan Timur Cabang Pembantu Tanah Kuning.

Pelayanan merupakan "kunci" utama dalam menentukan kepuasan nasabah atau pelanggan. Memberikan pelayanan terbaik kepada pelanggan akan memberikan kesan yang tidak akan terlupakan kepada pelanggan. Pelanggan akan merasa terlayani dengan baik, sehingga nantinya pelanggan tersebut akan merekomendasikan kepada orang lain agar menggunakan jasa pelayanan suatu perusahaan atau dalam penelitian ini adalah bank Pembangunan Daerah (BPD) capem Tanah Kuning.

Sehingga hipotesis yang menyatakan bahwa kualitas layanan berpengaruh terhadap kepuasan Nasabah Bank Pembangunan Daerah (BPD) Kalimantan Timur Cabang Pembantu Tanah Kuning adalah terbukti atau benar.

\section{SIMPULAN}

Simpulan dalam penelitian ini adalah kualitas layanan berpengaruh terhadap kepuasan Nasabah Bank Pembangunan Daerah (BPD) Kalimantan Timur Cabang Pembantu Tanah Kuning. Sebaiknya Memberikan pelatihan-pelatihan kepada front liner tentang pentingnya pelayanan yang baik kepada nasabah serta memberikan kenyamanan dalam hal fasilitas yang baik kepada nasabah. 


\section{Bibliography}

[1] M. Agustin, "Analisis Pengaruh Kualitas Pelayanan Perbankan Terhadap Kepuasan Nasabah Pada PT. Bank Niaga TBK," Jakarta, 2014.

[2] Irawan, 10 Prinsip Kepuasan Pelanggan, Jakarta: Elex Media Komputindo, 2003.

[3] B. Kaltim, "www.bankkaltim.co.id," Bank Kaltim, 1411 2010. [Online]. Available: http://www.bankaltim.co.id/pages/read/visi_dan_misi.html?ref=180. [Accessed 14 November 2015].

[4] Winardi, Marketing dan Perilaku Konsumen, Bandung: Mandar Maju, 2008. 